\title{
Highlights of the major progress in single-atom catalysis in 2015 and 2016
}

\author{
Bing Han a,b,†, Rui Lang a, ${ }^{\dagger}$, Botao Qiao a, ${ }^{\text {* }}$, Aiqin Wang a, Tao Zhang a \\ a State Key Laboratory of Catalysis, Dalian Institute of Chemical Physics, Chinese Academy of Sciences, Dalian 116023, Liaoning, China \\ b University of Chinese Academy of Sciences, Beijing 100049, China
}

\section{A R T I C L E I N F O}

\section{Article history:}

Received 24 April 2017

Accepted 7 June 2017

Published 5 September 2017

\section{Keywords:}

Single-atom catalysis

Catalyst synthesis

CO oxidation

Hydrogenation

Electrocatalysis

\begin{abstract}
A B S T R A C T
The idea that single metal atoms dispersed on a solid support can act as an efficient heterogeneous catalyst was raised in 2011 when single $\mathrm{Pt}$ atoms on an $\mathrm{FeO}_{x}$ surface were reported to be active for $\mathrm{CO}$ oxidation and preferential oxidation of $\mathrm{CO}$ in $\mathrm{H}_{2}$. The last six years have witnessed tremendous progress in the field of single-atom catalysis. Here we introduce the major achievements on this topic in 2015 and 2016. Some particular aspects of single-atom catalysis are discussed in depth, including new approaches in single-atom catalyst (SAC) synthesis, stable gold SACs for various reactions, the high selectivity of Pt and Pd SACs in hydrogenation, and the superior performance of non-noble metal SACs in electrochemistry. These accomplishments will encourage more efforts by researchers to achieve the controllable fabrication of SACs and explore their potential applications.
\end{abstract}

(C) 2017, Dalian Institute of Chemical Physics, Chinese Academy of Sciences. Published by Elsevier B.V. All rights reserved.

\section{Introduction}

Supported metal catalysts consisting of metals dispersed on high-surface-area materials are an important type of heterogeneous catalyst. Supported metal catalysts have been widely used in many industrial processes such as fine chemical production, the petrochemical industry, and automobile emission control [1]. To use metals more effectively in catalysis, they are usually finely divided into nanoparticles (NPs) with dimensions of 1-20 $\mathrm{nm}$. However, even at these dimensions, the catalytic efficiency of metals is still quite low because only the surface atoms on the NPs are used to catalyze reactions. To further improve catalytic efficiency, supported catalysts with atomic dispersion are highly desired to maximize atom efficiency. However, such catalysts are extremely difficult to make.
Since the start of this century, a few studies have suggested that non-metallic metal species/cations are the real active sites, or at least much more active than their NP counterparts, in several reactions including the water-gas shift (WGS) reaction [2], selective hydrogenation [3], and selective oxidation [4]. These studies shed new light on catalysis using isolated metal atoms. However, no attempt to fabricate supported catalysts consisting of only atomically dispersed isolated atoms on a support was reported until several years ago when an iron oxide-supported Pt single-atom catalyst (SAC) [5] was developed based on the concept of "single-atom catalysis" [5,6]. This development initiated interest in the topic of single-atom catalysis, which has drawn increasing attention ever since and progressed rapidly during the last few years [7-11]. In particular, novel SACs have been developed and new applications have

\footnotetext{
* Corresponding author. Tel: +86-411-84379416; Fax: +86-411-84685940; E-mail: bqiao@dicp.ac.cn

† These authors contributed equally to this work.

This work was supported by the National Natural Science Foundation of China (21606222, 21303184, 21573232), China Postdoctoral Science Foundation (2016M601350), Strategic Priority Research Program of the Chinese Academy of Sciences (XDB17020100), National Key Projects for Fundamental Research and Development of China (2016YFA0202801), and Department of Science and Technology of Liaoning Province (2015020086-101). DOI: 10.1016/S1872-2067(17)62872-9 | http://www.sciencedirect.com/science/journal/18722067 | Chin. J. Catal., Vol. 38, No. 9, September 2017
} 
been explored in the last two years. For example, several $\mathrm{Au}$ SACs have been intentionally developed. Several new methods to prepare SACs with high metal loading have also been devised. In addition, more and more non-noble metal SACs are being developed and the applications of SACs are being extended to many other reactions such as fine chemical synthesis and electrocatalysis. Here we summarize the major advances in this field that occurred in 2015 and 2016 with the aim of illustrating the scientific importance and practical usage of SACs. First, we introduce some novel synthetic methods developed recently to prepare SACs. Second, the remarkable performance of Au SACs in various reactions is described. Third, the superior selectivity of single-atom Pt and Pd catalysts in hydrogenation of $\mathrm{C}-\mathrm{C}$ bonds is discussed. Finally, electrochemical and photochemical conversion using SACs is considered.

\section{Novel synthetic approaches to obtain SACs}

The rational fabrication of SACs is not an easy task, because dispersed metal atoms with high surface free energy are usually unstable and tend to assemble to form larger aggregates during the synthesis and/or subsequent treatment processes. At present, most SACs prepared by wet chemistry methods that can be routinely performed in most laboratories have a very low level of metal loading to avoid aggregation. Recently, some new reliable methods to synthesize SACs with high loading have been developed.

\subsection{Atomic layer deposition}

The atomic layer deposition (ALD) method was developed to fabricate metal oxide thin films with atomically precise control [12], and was adapted to fabricate a stable Pt SAC in 2013 [13]. ALD could be a powerful method to synthesize uniformly dispersed SACs for fundamental studies, although a few disadvantages such as limited scalability, low growth rate, and high precursor cost may make it, at least in its present format, less practical in a commercial scale $[10,14-16]$.

In the past two years, a few supported Pd SACs prepared by ALD have shown good catalytic performance [17,18]. Lu's group [17] used the ALD technique to disperse Pd on a graphene support. Their $\mathrm{Pd}_{1}$ /graphene SACs catalyzed hydrogenation of 1,3-butadiene to butenes with about $100 \%$ butene selectivity at $95 \%$ conversion under mild reaction conditions. The authors suggested that the excellent selectivity was caused by the change of 1,3-butadiene adsorption mode and a favorable steric effect on the isolated Pd atoms (Fig. 1). Moreover, the $\mathrm{Pd}_{1}$ /graphene SAC showed high durability, resisting deactivation via metal atom aggregation or carbonaceous deposit formation during $100 \mathrm{~h}$ of stream reaction.

Piernavieja-Hermida et al. [18] prepared a Pd SAC by a two-step ALD process. First, a Pd precursor was adsorbed on an $\mathrm{Al}_{2} \mathrm{O}_{3}$ substrate. Aggregation of $\mathrm{Pd}$ atoms was avoided because of the presence of the large hexafluoroacetylacetonate (hfac) ligand. In the second step, $\mathrm{TiO}_{2}$ was selectively grown on the $\mathrm{Al}_{2} \mathrm{O}_{3}$ substrate but not on $\mathrm{Pd}(\mathrm{hfac})_{2}$, thus forming $\mathrm{TiO}_{2}$ nanocavities around the $\mathrm{Pd}(\mathrm{hfac})_{2}$ complex. After the ligands

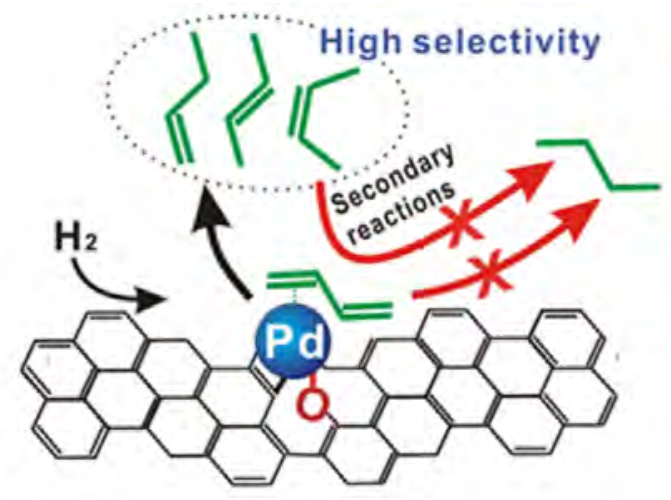

Fig. 1. Adsorption modes of $\mathrm{Pd}_{1} /$ graphene-catalyzed hydrogenative conversion of 1,3-butadiene to butenes. Reprinted with permission from Ref. [17]. Copyright 2015, American Chemical Society.

were removed, $\mathrm{TiO}_{2}$ nanocavity-protected $\mathrm{Pd}_{1}$ sites were formed. This Pd SAC displayed promising activity in the methanol decomposition reaction, but aggregated upon calcination or reduction at low temperature $\left(200-300{ }^{\circ} \mathrm{C}\right)$. In addition, a good balance of the reaction activity and stability was needed. When the surface Pd sites were covered by more $\mathrm{TiO}_{2}$ deposition cycles, the sintering of Pd atoms during heating treatment was hindered, but in the same time a lower activity was achieved.

\subsection{High-temperature vapor transport}

Datye et al. [19] reported an unexpected high-temperature vapor transport method to prepare Pt SACs by physically mixing $\mathrm{Pt} / \mathrm{La}-\mathrm{Al}_{2} \mathrm{O}_{3}$ catalyst with ceria powder under oxidizing conditions at high temperature. At $800{ }^{\circ} \mathrm{C}$ in flowing air, $\mathrm{Pt}$ molecules are emitted as mobile $\mathrm{PtO}_{2}$ and can be trapped on a ceria surface to form stable $\mathrm{Pt}_{1} / \mathrm{CeO}_{2} \mathrm{SACs}$. Three kinds of ceria with different surface facets were investigated; ceria cubes could only slow the sintering process of $\mathrm{Pt}$, while ceria rods and polyhedral ceria could effectively trap Pt species (Fig. 2). These catalysts exhibited good performance in the oxidation of $\mathrm{CO}$ to

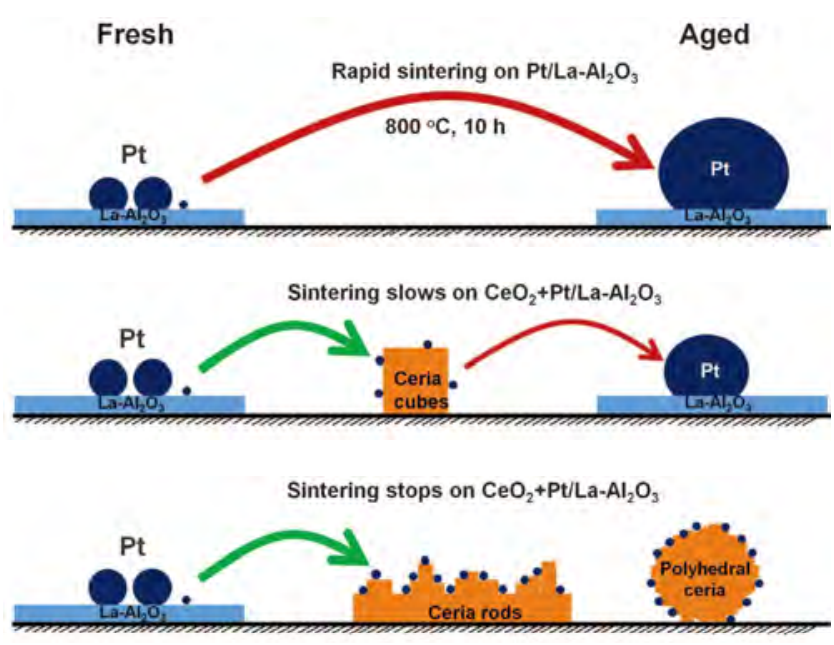

Fig. 2. Illustration of the sintering process of Pt nanoparticles under different conditions. Reprinted with permission from Ref. [19]. Copyright 2016, Science. 
$\mathrm{CO}_{2}$ and the Pt atoms in the SACs remained isolated during the reaction. Dvorak and colleagues [20] reported a series of characterization results together with density functional theory (DFT) calculations that suggested that single Pt atoms can be stabilized on the monoatomic step edges of a ceria support.

\subsection{The photochemical method}

Zheng et al. [21] developed a photochemical method to prepare a single-atom palladium-titanium oxide catalyst $\left(\mathrm{Pd}_{1} / \mathrm{TiO}_{2}\right)$ that involved dispersing $\mathrm{Pd}$ single atoms on ethylene glycolate (EG)-stabilized ultrathin $\mathrm{TiO}_{2}$ nanosheets. Exposing the catalyst to ultraviolet (UV) light resulted in the generation of EG radicals on the $\mathrm{TiO}_{2}$ surface. EG radicals were proposed to promote the formation of a $\mathrm{PdCl}_{1} / \mathrm{TiO}_{2}$ intermediate that was easily converted to $\mathrm{Pd}_{1} / \mathrm{TiO}_{2}$. The Pd loading density was high (up to $1.5 \%$ ). The $\mathrm{Pd}_{1} / \mathrm{TiO}_{2} \mathrm{SAC}$ exhibited high catalytic activity in hydrogenation of $\mathrm{C}=\mathrm{C}$ and $\mathrm{C}=\mathrm{O}$ bonds along with good stability.

\subsection{Pyrolysis}

Inspired by the general method to prepare carbon-based metal catalysts, $\mathrm{M}_{1}$ /carbon SACs can also be fabricated via pyrolysis. This procedure generally consists of two steps: incorporation of metal precursors into carbon precursors followed by high-temperature carbonization of the precursors under inert gas to obtain the carbon-supported metal atom catalysts. Zhang and Wang's group [22] synthesized a Co-N-C SAC by pyrolysis of cobalt-phenanthroline complexes on a mesoporous carbon support. The active sites in the $\mathrm{Co}-\mathrm{N}-\mathrm{C}$ catalyst are proposed to be Co single atoms bonded with $\mathrm{N}$ within graphitic sheets. This catalyst was used in $\mathrm{C}-\mathrm{C}$ bond-forming reactions to construct complex molecules from readily available simple substrates. The aerobic oxidative cross-coupling of primary and secondary alcohols to directly produce $\alpha, \beta$-unsaturated ketones was used as the probe reaction (Fig. 3), and high turnover frequency (TOF), good recyclability, and broad substrate scope were achieved. The TOF was calculated to be $3.8 \mathrm{~s}^{-1}$ based on Co single atoms, making it the most efficient catalyst in the literature to date.

The same group further applied the $\mathrm{Co}-\mathrm{N}-\mathrm{C}$ catalyst to the chemoselective hydrogenation of nitroarenes to produce azo compounds under mild reaction conditions. Combining

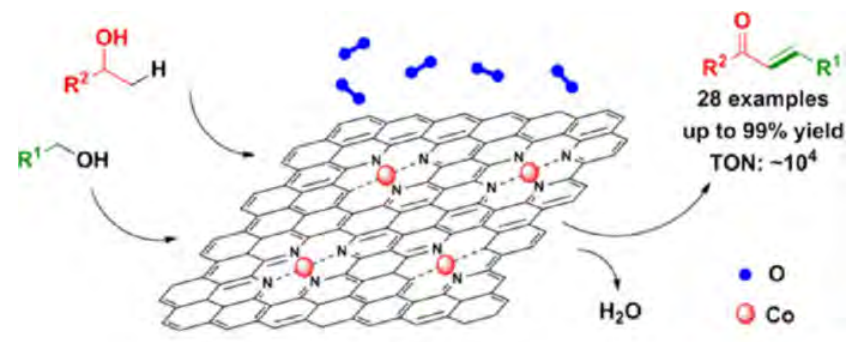

$\mathrm{O}_{2}$ balloon, LiOH, $70^{\circ} \mathrm{C}, 12-24 \mathrm{~h}$

Fig. 3. Aerobic oxidative cross-coupling on a Co-N-C single-atom catalyst. Reprinted with permission from Ref. [22]. Copyright 2015, American Chemical Society. high-angle annular dark field scanning transmission electron microscopy (HAADF-STEM), X-ray absorption fine structure (XAFS) spectroscopy, and density functional theory (DFT) calculation, the exact structure of the Co-N-C catalysts was revealed to be $\mathrm{CoN}_{4} \mathrm{C}_{8}-2 \mathrm{O}_{2}$. The Co center atom was coordinated to four pyridinic $\mathrm{N}$ atoms in the graphitic layer, while two oxygen molecules were weakly adsorbed on the Co atoms perpendicular to the Co- $\mathrm{N}_{4}$ plane. Determination of the accurate structure of the catalytic center helps us to understand the exceptional activity and chemoselectivity of the Co-N-C catalysts [23].

\subsection{One-pot synthesis}

A novel $\mathrm{Ru}$ SAC has been reported [24]. A one-pot wet chemical procedure was used to synthesize single $\mathrm{Ru}$ atoms on ultrathin Pd nanoribbons with a high metal loading of about 5.9 wt $\%$. The nanoribbons were composed of uniformly dispersed $\mathrm{Ru}$ and $\mathrm{Pd}$ atoms. The ultrathin $\mathrm{Pd} / \mathrm{Ru}$ nanoribbons showed higher catalytic performance in the selective hydrogenation of allyl benzyl ether than that of commercial $\mathrm{Ru} / \mathrm{C}$ and $\mathrm{Pd} / \mathrm{C}$ catalysts, without any hydrogenolysis of the O-benzyl group.

\subsection{Direct synthesis}

High-silica chabazite (CHA) with encapsulated Pt species (Pt/CHA) has been synthesized using an organic structure-directing agent and thiol-stabilized Pt precursor [25]. The $\mathrm{Pt} / \mathrm{CHA}$ catalyst hindered metal sintering under different conditions, even in $\mathrm{H}_{2}, \mathrm{O}_{2}$, and $\mathrm{H}_{2} \mathrm{O}$. Interestingly, Pt/CHA converted Pt nanoparticles to single Pt atoms under oxidizing conditions, which converted back under reducing conditions (Fig. 4). Pt/CHA catalyzed oxidation of ethylene but not propylene because of the small pores in CHA.

\section{Preparation of Au SACs}

The preparation of Au SACs is extremely difficult. One possible explanation for this may be that the electronegativity and ionization potential of $\mathrm{Au}$ are relatively high among those of transition metals. Consequently, Au is reluctant to donate an electron, and interacts rather weakly with many oxides [26]. Only recently have Au single atoms deposited on suitable ox-

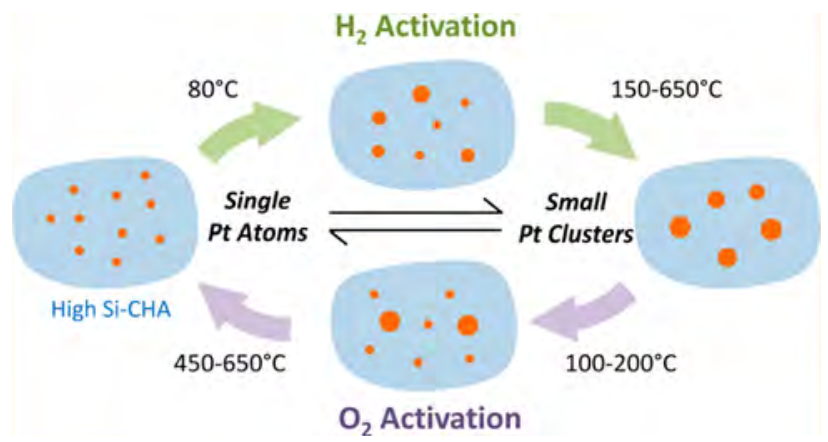

Fig. 4. Reversible interconversion of Pt nanoparticles into site-isolated single atoms in reducing and oxidizing atmospheres. Reprinted with permission from Ref. [25]. Copyright 2016, American Chemical Society. 
ides been successfully prepared by several groups. One of the most interesting applications of these Au SACs is CO oxidation.

\subsection{CO oxidation}

CO oxidation is of great importance in both fundamental studies and practical applications. Oxide-supported Au NPs are currently regarded as the most active catalysts for CO oxidation. The widely accepted active center is Au NPs and clusters within the size range of $0.5-5 \mathrm{~nm}$ [27]. Whether Au SACs are active or not still remains controversial. Some theoretical calculations suggested that supported Au SACs can be active $[28,29]$, even highly active $[30,31]$, for CO oxidation. However, experimental data obtained for both model [32] and practical catalysts [27] showed the opposite conclusion: Au single atoms were less active than Au NPs. In 2015, Zhang's group [33] experimentally demonstrated that $\mathrm{Au}$ single atoms deposited on several suitable oxides can be as active as Au NPs in terms of TOF and much more active in terms of specific rate because of the higher atomic efficiency. We have summarized this progress in detail in a recent minireview [33] and will not provide more introduction here.

\subsection{Ethanol dehydrogenation and diene hydrogenation}

Flytzani-Stephanopoulos et al. [34] prepared atomically dispersed $\mathrm{Au}$ supported on nanoscale $\mathrm{ZnZrO}_{x}$ composite oxides, and investigated this catalyst in the low-temperature ethanol dehydrogenation reactions to form acetaldehyde and acetone. The composite $\mathrm{ZnZrO}_{x}$ support stabilized $\mathrm{Au}$ atoms against growth much better than either of the neat oxides. The acidity of the $\mathrm{ZrO}_{2}$ surface was modulated by $\mathrm{ZnO}$, and the undesired dehydration reactions were suppressed by optimizing $\mathrm{ZnO}$ distribution, which preserved the active $\mathrm{Au}-\mathrm{O}_{x}$ surface species under the investigated reaction conditions.

In homogeneous catalytic hydrogenations of alkenes, the initial step is the oxidative addition of an $\mathrm{H}_{2}$ molecule to the metal center to generate an active metal dihydride species. The two $\mathrm{H}$ atoms from the $\mathrm{H}_{2}$ molecule often end up in the same product molecule. Therefore, when parahydrogen (molecular hydrogen with the spins of its two protons aligned antiparallel) is used, such pairwise hydrogen addition can preserve the quantum correlation of its nuclear spins. Correspondingly, the nuclear magnetic resonance (NMR) spectra of the product molecules may exhibit a very strong signal enhancement, termed parahydrogen-induced polarization (PHIP). However, unlike the well-defined single metal center-catalyzed homogeneous hydrogenation, heterogeneous hydrogenation proceeds over the larger surface of a metal NP or cluster. The general mechanism of heterogeneous hydrogenation involves dissociative chemisorption of hydrogen on the metal surface, which creates a surface $\mathrm{H}$ pool. These $\mathrm{H}$ atoms can move over the surface, and the corresponding relaxation processes gradually destroy the original spin correlation. As a result, noble metal NP/clustercatalyzed heterogeneous hydrogenations do not occur according to the pairwise addition mechanism.

If the chemical properties of heterogeneous atomically dis- persed catalysts are similar to those of homogeneous catalysts, and the reaction mechanisms are similar, PHIP effects in hydrogenations may be observed. In as early as 2005, isolated $\mathrm{Au}^{3+}$ ions at the surface of zirconia was found to be active for selective hydrogenation of 1,3-butadiene [3], but the mechanism of hydrogen activation still need to be elucidated. In 2015, a supported Au SAC was demonstrated to be active in pairwise hydrogen addition [35]. Corma et al. [35] dispersed single $\mathrm{Au}$ atoms on multiwalled carbon nanotubes (MWCNTs) to synthesize a highly isolated monoatomic Au catalyst. The Au/MWCNT SAC was found to be effective in hydrogenation of 1,3-butadiene and 1-butyne with parahydrogen, and the estimated contributions from the pairwise hydrogen addition route were at least an order of magnitude higher than those for supported metal NPs. Therefore, this protocol may be potentially used to produce hyperpolarized fluids to enhance NMR signals. The proposed mechanism of 1,3-butadiene hydrogenation with parahydrogen over the highly isolated monoatomic $\mathrm{Au} /$ MWCNT SAC was through pairwise hydrogen addition, which is similar to that of homogeneous hydrogenation.

\section{Selective hydrogenation using Pt and Pd SACs}

Pt SACs are perhaps the most extensively studied [13,36-38] among various SACs developed since their first report in 2011 [5]. In 2015, there were also many new reports related to Pt SACs that exhibited extraordinary activity in a large number of reactions, such as the WGS reaction $[39,40]$, hydrogenation of 1,3-butadiene to butenes [41], and electrocatalytic splitting of water [42]. Similar to their earlier findings [39], Flytzani-Stephanopoulos' group suggested that the Pt atoms stabilized by the presence of Na were highly active in the WGS reaction [40] and Pt atoms alloyed with other metals were highly selective in hydrogenation [41]. Interestingly, Lin et al. [43] found that in the reduction of $\mathrm{NO}_{2}$ by $\mathrm{H}_{2}$, their $0.06 \mathrm{wt} \%$ $\mathrm{Pt} / \mathrm{FeO}_{x}$ catalyst exhibited better performance in terms of both $\mathrm{NO}_{2}$ conversion and $\mathrm{N}_{2}$ selectivity than $\mathrm{FeO}_{x}$-supported Pt $(1.22$ wt\%) NPs prepared by a colloidal method. This was the first report revealing that SACs with much lower metal loading can have higher overall conversion than colloidal nanocatalysts, confirming the high atomic efficiency of SACs. In 2014, the same group reported that the catalytic hydrogenation of nitroarenes can be performed using $\mathrm{FeO}_{x}$-supported $\mathrm{Pt}$ single-atom and pseudo-single-atom structures as highly active, chemoselective, and reusable catalysts. In hydrogenation of 3-nitrostyrene, the TOF of the catalyst was about $1500 \mathrm{~h}^{-1}$, and the selectivity for 3-aminostyrene was close to $99 \%$. This promising performance can be attributed to the presence of positively charged Pt centers and the absence of Pt-Pt metallic bonding, both of which favor the preferential adsorption of nitro groups [44]. Because of the unique adsorption properties of SACs, more examples of excellent selectivity in hydrogenation were reported in the two years considered in this review.

Yan et al. [45] reported a high-loading Pt SAC with good performance in hydrogenation of nitro and ketone substrates. Based on the coordination chemistry, noble metals with a low valence state can be stable and single atomically dispersed. 
Consequently, Pt single atoms anchored at four-coordinate sites of phosphomolybdic acid $\left(\mathrm{H}_{3} \mathrm{PMo}_{12} \mathrm{O}_{40}\right.$, PMA) can be prepared by an impregnation method, because PMA has several coordination locations. DFT calculations and X-ray absorption near-edge structure (XANES) analysis were used to determine the metal atom binding sites and electronic state of the catalyst, revealing that $\mathrm{Pt}$ atoms were coordinated with four bridging oxygen atoms with quasi square-planar geometry and the $\mathrm{Pt}$ species were positively charged.

Pd is another noble metal that has shown catalytic activity in various reactions with atomic dispersion [4,46]. In 2000, Abbet and co-workers [46] studied the cyclotrimerization of acetylene on $\mathrm{MgO}(100)$-supported $\operatorname{Pd}_{n}(1 \leq n \leq 30)$ clusters. Their temperature-programmed reduction results showed that benzene desorbs at around $300 \mathrm{~K}$ on $\mathrm{Pd}_{1} / \mathrm{MgO}$, suggesting that isolated Pd atoms can catalyze this reaction, although its activity was relatively low compared with that of Pd clusters containing more than three atoms. Different from this, Hackett et al. [4] showed that atomically dispersed $\mathrm{Pd}^{\mathrm{II}}$ on $\mathrm{Al}_{2} \mathrm{O}_{3}$ was much more active for the selective aerobic oxidation of allylic alcohols than Pd clusters and NPs on the same support. However, there have been few studies on Pd SACs $[47,48]$. Only in the last year have Pd SACs attracted new attention, especially in selective hydrogenation.

Perez-Ramirez and colleagues [49] anchored Pd atoms into the cavities of mesoporous polymeric graphitic carbon nitride to obtain a single-site Pd catalyst that showed good performance in three-phase hydrogenations of alkynes and nitroarenes in a continuous-flow reactor. The SAC displayed higher reactivity and product selectivity than those of Pd NP benchmark catalysts. The atomic dispersion of Pd species throughout the sample was confirmed by microscopic examination and XAFS spectroscopy. DFT calculations provided fundamental insights into the material structure. The high catalytic activity and selectivity were attributed to the facile hydrogen activation and hydrocarbon adsorption on atomically dispersed Pd sites. In the gas phase reaction, our group [50] also found that a Pd/ZnO SAC presented high activity in semihydrogenation of acetylene.

Doping isolated dispersed metal atoms into a second metal substrate is an intriguing method to synthesize single-atom alloy catalysts (SAAs). Isolation of Pd atoms with another metal element by forming alloys is an effective method to adjust the electronic, adsorption, and catalytic behavior of Pd catalysts, as had been demonstrated before [51-53]. Last year, several Pd alloyed catalysts with different $\mathrm{Pd} /$ metal ratios were newly developed, including Pd-Ag [54] and $\mathrm{Pd}-\mathrm{Cu}$ [55]. The SAAs were highly selective in the semihydrogenation of acetylene in an ethylene-rich stream. These SAAs were prepared by a simple incipient wetness co-impregnation method with only ppm levels of Pd, but they can overcome the major disadvantages of traditional monometallic Pd catalysts, such as over-hydrogenation to ethane, and the formation of carbonaceous deposits. The good performance of these SAAs was mainly ascribed to the Pd atoms isolated by the other metal atoms. Meyer's group [56] also reported that $\mathrm{Pd}-\mathrm{Ag}$ alloy was an efficient catalyst in hydrogenation of acrolein.

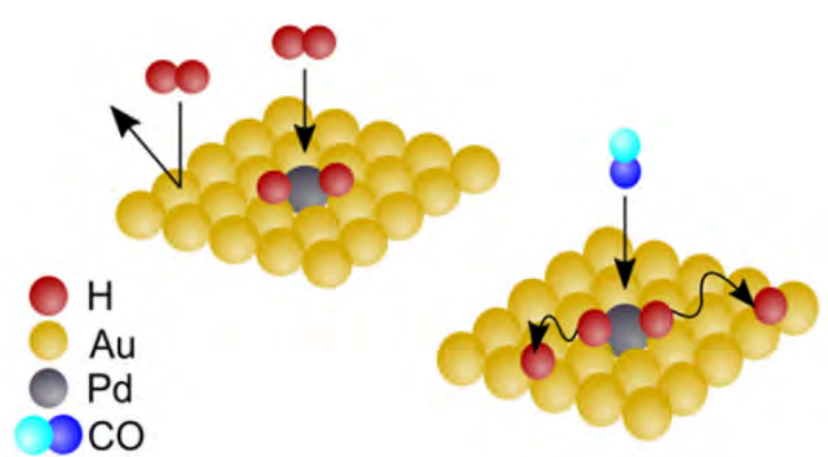

Fig. 5. Schematics of $\mathrm{H}_{2}$ adsorption and desorption (left) and the $\mathrm{CO}$ poisoning effect (right). Reprinted with permission from Ref. [57]. Copyright 2016, American Chemical Society.

Sykes et al. [57] demonstrated that single Pd atoms in $\mathrm{Pd}-\mathrm{Au}$ surface alloys can activate hydrogen. Compared with $\mathrm{Au}(111), \mathrm{Pd}-\mathrm{Au}$ SAAs have a much lower activation barrier for $\mathrm{H}_{2}$ dissociation. $\mathrm{H}$ adatoms weakly bond to Pd atoms; therefore, $\mathrm{H}$ atoms will spread from $\mathrm{Pd}$ atoms to the $\mathrm{Au}$ surface in $\mathrm{Pd}-\mathrm{Au}$ SAAs. The authors also investigated the adsorption of $\mathrm{CO}$ on $\mathrm{Pd}-\mathrm{Au}$ SAAs. Combining temperature-programmed desorption analysis and DFT calculations revealed that CO can occupy Pd sites and lead to $\mathrm{H}_{2}$ desorption and catalyst poisoning (Fig. 5).

The interaction of $\mathrm{CO}$ and $\mathrm{H}$ with $\mathrm{Pt}$ sites on a Pt-Cu SAA was investigated by catalysis and surface science technology [58]. The binding strength of $\mathrm{CO}$ on isolated Pt atoms in the $\mathrm{Pt}-\mathrm{Cu}$ SAA is weaker than that of $\mathrm{CO}$ with other Pt clusters. Consequently, the Pt-Cu SAA catalyst can have more active $\mathrm{Pt}$ sites with good CO tolerance. Scanning tunneling microscopy experiments indicated that $\mathrm{H}_{2}$ activation occurs at $\mathrm{CO}$-free $\mathrm{Pt}$ sites and then $\mathrm{H}$ adatoms move away from Pt sites.

\section{Other interesting conversions}

Apart from the reactions discussed above, SACs are also effective in other interesting conversions, such as NO reduction, $\mathrm{CO}_{2}$ reduction, hydroformylation, and formaldehyde oxidation, so here we give a brief summary of them.

The adsorption and dissociation of reactant molecules on a catalyst surface strongly depend on the composition of the catalytic site, which typically consists of one or more atoms. After a guest metal $\mathrm{M}$ is deposited on a support surface, synthesis of an isolated bimetallic site is quite challenging, because the over-reduction of the support $\mathrm{A}_{x} \mathrm{O}_{y}$ typically produces an ultrathin bimetallic film of metals $\mathrm{M}$ and $\mathrm{A}$. In contrast, weaker reduction at a relatively low temperature does not remove oxygen atoms between $\mathrm{M}$ and $\mathrm{A}$ of $\mathrm{M}_{1} \mathrm{O}_{n} / \mathrm{A}_{x} \mathrm{O}_{y}$, so $\mathrm{M}$ still bonds to the surface oxygen atoms and no bimetallic $\mathrm{M}_{1} \mathrm{~A}_{n}$ site can form. Tao et al. [59] recently reported the controllable synthesis of singly dispersed bimetallic $\mathrm{Rh}_{1} \mathrm{Co}_{3}$ sites. They used an appropriate reduction method and transformed the catalyst precursor $\mathrm{M}_{1} \mathrm{O}_{n} / \mathrm{A}_{x} \mathrm{O}_{y}$ into a catalyst consisting of isolated $\mathrm{M}_{1} \mathrm{~A}_{n}$ bimetallic sites (Fig. 6), singly dispersed bimetallic $\mathrm{Rh}_{1} \mathrm{Co}_{3}$ sites in this case. The isolated bimetallic catalyst exhibited promising performance in reduction of nitric oxide with CO and 100\% selectivity for $\mathrm{N}_{2}$ production at a low temperature of $\sim 110{ }^{\circ} \mathrm{C}$. 
a

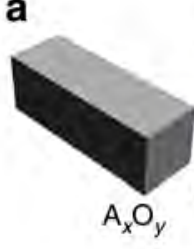

b

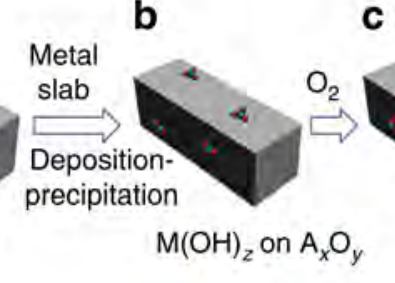

$\mathrm{M}(\mathrm{OH})_{z}$ on $\mathrm{A}_{x} \mathrm{O}_{y}$ c

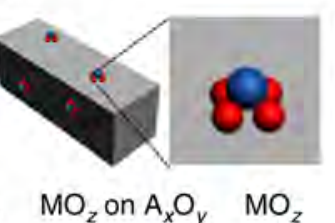

d

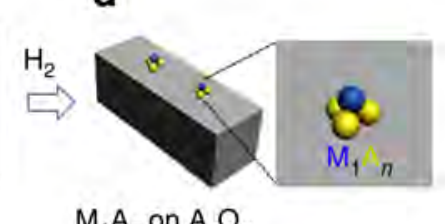

$\mathrm{M}_{1} \mathrm{~A}_{n}$ on $\mathrm{A}_{x} \mathrm{O}_{y}$

\section{$\bigcirc \mathrm{M} \odot \mathrm{O} \cdot \mathrm{H} \quad \mathrm{A} \otimes \mathrm{A}_{x} \mathrm{O}_{y}$}

Fig. 6. Synthesis of a catalyst with single dispersed bimetallic sites $\left(\mathrm{M}_{1} \mathrm{~A}_{n}\right)$. Reprinted with permission from Ref. [59]. Copyright 2015, Nature.

After characterization and DFT calculations, the authors suggested that the unique cationic state of the singly dispersed bimetallic site and the minimized binding configurations of reactant molecules were vital to the high selectivity of their catalyst.

Christopher's group [60] reported strong correlations between the TOF of the catalytic reverse WGS and the fraction of $\mathrm{Rh}$ atomically dispersed isolated sites as well as between the TOF of catalytic methanation and the fraction of Rh nanoparticles sites. The selectivity difference between isolated atoms and NPs of the same metal on the same support was further demonstrated in competing parallel reaction pathways of $\mathrm{CO}_{2}$ reduction by $\mathrm{H}_{2}$.

Recently, Lang et al. [61] demonstrated that $\mathrm{ZnO}$ nanowire-supported single-atom Rh catalysts had similar efficiency (turnover number (TON) of 40000) for the hydroformylation of olefins to that of the homogeneous Wilkinson's catalyst (TON of 19000). HAADF-STEM and infrared CO chemisorption measurements identified the presence of isolated $\mathrm{Rh}$ atoms on the support. Meanwhile, X-ray photoelectron spectra and XANES spectra indicated that the electronic state of Rh was almost metallic. The catalysts were about one or two orders of magnitude more active than most reported heterogeneous catalysts in the hydroformylation of a series of olefins. This work experimentally demonstrated for the first time that single-atom catalysis might bridge hetero- and homogeneous catalyses and the development of suitable SACs might be a new way to realize heterogenization of homogeneous catalysts.

Almost at the same time, Wang and co-workers [62] reported a $\mathrm{Rh} / \mathrm{CoO}$ SAC for hydroformylation of propene with high regioselectivity. The linear product butyraldehyde achieved a high yield of $94.4 \%$. This unexpected behavior suggests that the support in SACs may play a similar role in changing the substrate adsorption to that of ligands in homogeneous complexes.

In 2012, Tang's group [63] developed a special type of SAC; i.e., hollandite manganese oxide (HMO)-supported Ag SACs. In the past years, they have studied this catalyst system extensively and extended its application considerably [63-67]. For example, through in situ characterization, they directly observed the disintegration process of Ag NPs and then studied the dynamic formation of atomically dispersed $\mathrm{Ag}$ catalysts [64]. They also demonstrated that single Ag atoms can facilitate the activation of both lattice oxygen and gas oxygen because of their different electronic structure from that of bulk Ag, thus effectively promoting their catalytic performance in a few oxidation reactions such as formaldehyde elimination and benzene oxidation [65,66]. This type of Ag SAC therefore shows potential in environmental protection. To prevent $\mathrm{Ag}$ atoms from entering the tunnels in HMO to further increase the surface Ag active sites, the authors synthesized HMO NPs with a low aspect ratio and tunnels fully occupied with potassium ions to achieve high activity [67]. This represents a new approach for the rational design of this type of SAC. In addition, they also studied the promoting effect of potassium and found that surface-isolated potassium atoms on HMO with hybridized d-sp orbitals can specifically activate oxygen to enhance the activity of the catalyst in oxidation reactions [68].

\section{Use of SACs in electrocatalysis and photocatalysis}

Electroreduction of water to hydrogen is a promising method to obtain a sustainable supply of clean energy, but its large-scale application relies on the development of efficient catalysts. On one hand, highly dispersed Pt-based catalysts are an ideal option to achieve high atomic efficiency, while on the other hand, inexpensive non-noble metals are being developed to replace precious metal Pt catalysts. Here, we emphasize the recent achievements in Pt and non-noble metal SACs.

Last year, Bao et al. [42] demonstrated that the hydrogen evolution reaction (HER) activity of in-plane $\mathrm{S}$ atoms of 2D $\mathrm{MoS}_{2}$ can be triggered via single Pt atom doping. According to their DFT calculations, the tuned $\mathrm{H}$ adsorption behavior on the in-plane S sites neighboring Pt atoms is the origin of the high efficiency of this catalyst in the HER.

Lee and colleagues [69] produced hydrogen peroxide through electrochemical oxygen reduction. They prepared a Pt SAC supported on TiN NPs. Isolated single-atom Pt active sites catalyzed the reaction via a two-electron pathway, achieving high selectivity. Usually, two adjacent active sites can adsorb the two $\mathrm{O}$ atoms of $\mathrm{O}_{2}$ and break the $\mathrm{O}=\mathrm{O}$ double bond to form $\mathrm{H}_{2} \mathrm{O}$, but a single atom of Pt would not be able to break the strong $\mathrm{O}=\mathrm{O}$ bond. However, this catalyst achieved an unprecedented high mass activity for electrochemical $\mathrm{H}_{2} \mathrm{O}_{2}$ production. The same group also investigated the activity of SACs with different Pt loading in the oxidation of formic acid and methanol. Isolated SACs followed a two-electron pathway in formic acid oxidation and displayed no activity in methanol oxidation, 
while Pt NP catalysts followed a four-electron pathway in formic acid oxidation. A variety of transition metal single atoms anchored on defective graphene were investigated for $\mathrm{CO}_{2}$ electroreduction [70]. Calculation of free energies revealed that these SACs could selectively perform the $\mathrm{CO}_{2}$ reduction reaction and HER. In particular, a single Pt atom supported by double-vacancy graphene has the least negative predicted limiting potential $(-0.27 \mathrm{~V})$ for $\mathrm{CH}_{3} \mathrm{OH}$ production among the current catalysts.

Pt SACs have also been demonstrated to improve photocatalytic $\mathrm{H}_{2}$ evolution performance [71]. The isolated Pt atoms on $2 \mathrm{D}$ graphitic carbon nitride $\left(\mathrm{g}-\mathrm{C}_{3} \mathrm{~N}_{4}\right)$ are highly stable, and a variety of characterization results showed that Pt atoms located on the top of the five-membered $\mathrm{C}_{3} \mathrm{~N}_{4}$ rings can modify the surface trap states of g- $\mathrm{C}_{3} \mathrm{~N}_{4}$.

Atomically dispersed non-precious metal (i.e., Fe, Co, and $\mathrm{Ni}$ catalysts have showed unexpectedly high catalytic activity, especially in electrochemistry. Recently, Co [72] and Ni [73] single atoms supported on graphene have been reported by two individual groups; both of these catalysts showed superior electrocatalytic activity in the target reaction with low overpotentials. Tour's group [72] synthesized individual Co atoms dispersed on nitrogen-doped graphene, and used a variety of characterization techniques to identify the active sites associated with the unusual atomic nitrogen-metal constitution. Chen et al. [73] anchored single-atom $\mathrm{Ni}$ dopant atoms to 3D nanoporous graphene. The resulting catalyst showed superior HER reactivity with an overpotential of approximately $50 \mathrm{mV}$ and a Tafel slope of $45 \mathrm{mV} / \mathrm{dec}$ in $0.5 \mathrm{~mol} / \mathrm{L}$ of $\mathrm{H}_{2} \mathrm{SO}_{4}$ solution. In contrast to conventional Ni-based catalysts and graphene, experimental and theoretical investigations suggested that the unusual catalytic performance of this catalyst originates from $s p-d$ orbital charge transfer between the Ni dopant atoms and surrounding $C$ atoms. The resultant local structure with empty C-Ni hybrid orbitals is catalytically active and electrochemically stable.

A stable Co SAC with high metal loading was fabricated and used in the oxygen reduction reaction (ORR) with high activity [74]. A Zn/Co bimetallic metal-organic framework (MOF) with a molar ratio above 1:1 was synthesized as the catalyst precursor. The $\mathrm{Zn}$ atoms separated the Co atoms, preventing Co aggregation during high-temperature pyrolysis. During heat treatment, the $\mathrm{Zn}$ atoms evaporated and Co atoms were re- duced and embedded in the MOF-based porous carbon. The resulting $\mathrm{Co} / \mathrm{N}-\mathrm{C}$ SAC exhibited outstanding activity among Co $\mathrm{NP} / \mathrm{N}-\mathrm{C}$ and commercial Pt/C catalysts. $\mathrm{Co}-\mathrm{N}_{4}$ species were proposed as the active sites and facilitated the four-electron reduction process in the ORR.

The unique properties of SACs and metalloproteins can be combined to prepare metal-organic network catalysts that have two single-atom catalytic centers. These heterobimetallic catalysts can be used in the oxygen evolution reaction (OER) [75]. In this catalyst system, the single metal atoms have two different coordination environments. One metal is the center of porphyrin, and the other metal is coordinated by four pyridyl groups between the molecules. The second metal could enhance the activity of metal pyridyl-porphyrin ( $\left.{ }^{1} \mathrm{TPy}\right)$. The synergistic effects of $\mathrm{Co}(\mathrm{II})$ and $\mathrm{Fe}(\mathrm{II})$ metal species can increase the activity of the FeTPyP-Co network. Comparing catalysts with different metal centers revealed that the pyridyl-Co moiety is the critical site for the OER.

A catalyst consisting of single Co atoms attached to four nitrogen atoms in graphene nanosheets $\left(\mathrm{CoN}_{4} / \mathrm{GN}\right)$ has been studied [76]. $\mathrm{CoN}_{4} / \mathrm{GN}$ is a highly active and stable counter electrode for the interconversion of the $\mathrm{I}^{-} / \mathrm{I}_{3}-$ redox couple, and even showed better performance than that of conventional $\mathrm{Pt}$ electrodes.

Non-noble metal SACs have also displayed good performance in photocatalysis. Ye's group [77] developed MOF materials incorporating Co single atoms for $\mathrm{CO}_{2}$ reduction. The large surface area of Co SACs can enhance $\mathrm{CO}_{2}$ adsorption and activation. Additionally, the presence of Co atoms can suppress electron-hole recombination, which is a major disadvantage of current photocatalysts.

\section{Conclusions}

In the last two years, the achievements of single-atom catalysis in various conversions have been pronounced. Therefore, we anticipate that more novel SACs will be successfully prepared, and their potential applications explored in this exciting research field. However, this field is emerging, so many issues remain to be resolved in the near future. Regarding catalyst preparation, although many new SAC synthesis methods have been designed, their limitations are still considerable. For example, ALD might be suitable to fabricate uniformly dispersed

\section{Graphical Abstract}

Chin. J. Catal., 2017, 38: 1498-1507 doi: 10.1016/S1872-2067(17)62872-9

\section{Highlights of the major progress in single-atom catalysis in 2015 and 2016}

Bing Han, Rui Lang, Botao Qiao *, Aiqin Wang, Tao Zhang Dalian Institute of Chemical Physics, Chinese Academy of Sciences; University of Chinese Academy of Sciences

The latest developments in single-atom catalysis are highlighted, including new approaches in single-atom catalyst (SAC) synthesis, stable gold SACs, highly selective platinum and palladium SACs, and non-noble metal SACs in electrochemistry.

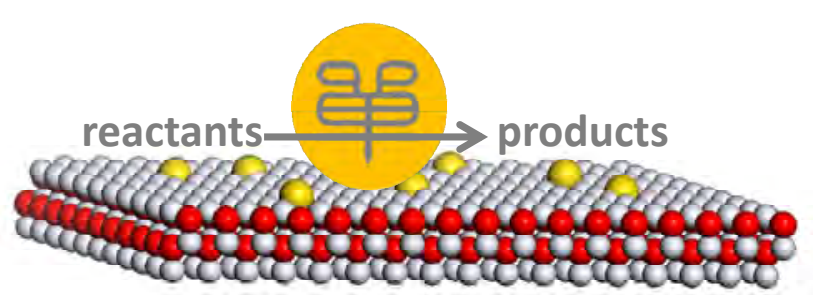


SACs, but it is currently unsuitable to produce catalysts on a commercial scale because of its high cost and low yield. Meanwhile, the scope of high-temperature vapor transport is limited to specific metals and supports. In addition, the extremely high temperature used is also a concern; it is not only energy consuming but also might deactivate the samples because of the over-strong interaction induced between metal atoms and supports. The pyrolysis method is limited to the synthesis of carbon-supported catalysts and requires metals that have suitable precursors. To date, the most simple and versatile methods to prepare SACs might be still the adsorption, deposition-precipitation, and co-precipitation methods, which all suffer from low metal loading. As for the catalytic performance, the role of supports should be further clarified. Because each metal atom contacts with the support in a SAC, the support may play a more important role compared with the case in nanocatalysts. It is generally accepted that in oxidation reactions, oxide supports can promote and even directly participate in the reactions by providing activated 0 . However, the role of supports in hydrogenation reactions has not been evaluated, even though it should also be important because disassociation of $\mathrm{H}_{2}$ on single atoms is generally believed to be difficult. Therefore, the effect of the support on SAC performance in hydrogenation reactions should be considered in future studies. Besides the above, some basic issues should also be deeply investigated in ongoing research. First, the differences in catalytic behavior between SACs and the corresponding homo-/heterogeneous catalysts should be studied to unveil the origin of the superior activity of SACs. Second, advanced in situ characterization methodologies should be used to monitor the dynamic formation of atomically dispersed active species. Third, the fine structure of active sites needs to be investigated by combining experimental results and computational approaches.

\section{References}

[1] G. Ertl, H. Knözinger, F. Schüth, J. Weitkamp, Handbook of Heterogeneous Catalysis, 2nd ed., Wiley-VCH, Weinheim, German, 2008.

[2] Q. Fu, H. Saltsburg, M. Flytzani-Stephanopoulos, Science, 2003, 301, 935-938.

[3] X. Zhang, H. Shi, B. Q. Xu, Angew. Chem. Int. Ed., 2005, 44, 7132-7135.

[4] S. F. J. Hackett, R. M. Brydson, M. H. Gass, I. Harvey, A. D. Newman, K. Wilson, A. F. Lee, Angew. Chem. Int. Ed., 2007, 46, 8593-8596.

[5] B. T. Qiao, A. Q. Wang, X. F. Yang, L. F. Allard, Z. Jiang, Y. T. Cui, J. Y. Liu, J. Li, T. Zhang, Nat. Chem., 2011, 3, 634-641.

[6] X. F. Yang, A. Q. Wang, B. T. Qiao, J. Y. Li, J. Y. Liu, T. Zhang, Acc. Chem. Res., 2013, 46, 1740-1748.

[7] J. Mitch, Chem. Eng. News, 2016, 94, 26.

[8] S. X. Liang, C. Hao, Y. T. Shi, ChemCatChem, 2015, 7, 2559-2567.

[9] Y. Y. Jin, P. P. Hao, J. Ren, Z. Li, Progr. Chem., 2015, 27, 1689-1704.

[10] J. Y. Liu, ACS Catal., 2017, 7, 34-59.

[11] C. Y. Wang, M. Yang, M. Flytzani-Stephanopoulos, AIChE J., 2016, 62, 429-439.

[12] E. Ahvenniemi, A. R. Akbashev, S. Ali, M. Bechelany, M. Berdova, S. Boyadjiev, D. C. Cameron, R. Chen, M. Chubarov, V. Cremers, A. Devi, V. Drozd, L. Elnikova, G. Gottardi, K. Grigoras, D. M. Hausmann, C. S. Hwang, S. H. Jen, T. Kallio, J. Kanervo, I. Khmelnitskiy, D. H. Kim, L. Klibanov, Y. Koshtyal, A. O. I. Krause, J. Kuhs, I. Kärkkänen,
M.L. Kääriäinen, T. Kääriäinen, L. Lamagna, A. A. Łapicki, M. Leskelä, H. Lipsanen, J. Lyytinen, A. Malkov, A. Malygin, A. Mennad, C. Militzer, J. Molarius, M. Norek, Ç. Özgit-Akgün, M. Panov, H. Pedersen, F. Piallat, G. Popov, R. L. Puurunen, G. Rampelberg, R. H. A. Ras, E. Rauwel, F. Roozeboom, T. Sajavaara, H. Salami, H. Savin, N. Schneider, T. E. Seidel, J. Sundqvist, D. B. Suyatin, T. Törndahl, J. R. van Ommen, C. Wiemer, O. M. E. Ylivaara, O. Yurkevich, J. Vac. Sci. Technol. A, 2017, 35, 010801.

[13] S. H. Sun, G. X. Zhang, N. Gauquelin, N. Chen, J. G. Zhou, S. L. Yang, W. F. Chen, X. B. Meng, D. S. Geng, M. N. Banis, R. Y. Li, S. Y. Ye, S. Knights, G. A. Botton, T. K. Sham, X. L. Sun, Sci. Rep., 2013, 3, 1775-1783.

[14] S. J. Jeong, Y. Gu, J. Heo, J. Yang, C. S. Lee, M. H. Lee, Y. Lee, H. Kim, S. Park, S. W. Hwang, Sci. Rep., 2016, 6, 20907.

[15] M. Leskela, M. Ritala, Angew. Chem. Int. Ed., 2003, 42, 5548-5554.

[16] H. Kim, J. Vac. Sci. Technol. B, 2003, 21, 2231-2261.

[17] H. Yan, H. Cheng, H. Yi, Y. Lin, T. Yao, C. L. Wang, J. J. Li, S. Q. Wei, J. L. Lu, J. Am. Chem. Soc., 2015, 137, 10484-10487.

[18] M. Piernavieja-Hermida, Z. Lu, A. White, K. B. Low, T. P. Wu, J. W. Elam, Z. L. Wu, Y. Lei, Nanoscale, 2016, 8, 15348-15356.

[19] J. Jones, H. F. Xiong, A. T. DeLaRiva, E. J. Peterson, H. Pham, S. R. Challa, G. S. Qi, S. Oh, M. H. Wiebenga, X. I. Pereira Hernández, Y. Wang, A. K. Datye, Science, 2016, 353, 150-154.

[20] F. Dvorak, M. Farnesi Camellone, A. Tovt, N. D. Tran, F. R. Negreiros, M. Vorokhta, T. Skala, I. Matolinova, J. Myslivecek, V. Matolin, S. Fabris, Nat. Commun., 2016, 7, 10801.

[21] P. X. Liu, Y. Zhao, R. X. Qin, S. Q. Mo, G. X. Chen, L. Gu, D. M. Chevrier, P. Zhang, Q. Guo, D. D. Zang, B. H. Wu, G. Fu, N. F. Zheng, Science, 2016, 352, 797-800.

[22] L. L. Zhang, A. Q. Wang, W. T. Wang, Y. Q. Huang, X. Y. Liu, S. Miao, J. Y. Liu, T. Zhang, ACS Catal, 2015, 5, 6563-6572.

[23] W. G. Liu, L. L. Zhang, W. S. Yan, X. Y. Liu, X. F. Yang, S. Miao, W. T. Wang, A. Q. Wang, T. Zhang, Chem. Sci. 2016, 7, 5758-5764.

[24] J. J. Ge, D. S. He, W. X. Chen, H. X. Ju, H. Zhang, T. T. Chao, X. Q. Wang, R. You, Y. Lin, Y. Wang, J. F. Zhu, H. Li, B. Xiao, W. X. Huang, Y. Wu, X. Hong, Y. P. Li, J. Am. Chem. Soc., 2016, 138, 13850-13853.

[25] M. Moliner, J. E. Gabay, C. E. Kliewer, R. T. Carr, J. Guzman, G. L. Casty, P. Serna, A. Corma, J. Am. Chem. Soc., 2016, 138, 15743-15750.

[26] T. Risse, S. Shaikhutdinov, N. Nilius, M. Sterrer, H. J. Freund, Acc. Chem. Res., 2008, 41, 949-956.

[27] M. Haruta, Faraday Discuss., 2011, 152, 11-32.

[28] K. K. Mao, L. Li, W. H. Zhang, Y. Pei, X. C. Zeng, X. J. Wu, J. L. Yang, Sci. Rep., 2014, 4, 5441.

[29] H. C. Fang, Z. H. Li, K. N. Fan, Phys. Chem. Chem. Phys., 2011, 13, 13358-13369.

[30] Y. G. Wang, D. H. Mei, V. A. Glezakou, J. Li, R. Rousseau, Nat. Commun., 2015, 6, 6511.

[31] M. F. Camellone, S. Fabris, J. Am. Chem. Soc., 2009, 131, 10473-10483.

[32] A. Sanchez, S. Abbet, U. Heiz, W. D. Schneider, H. Häkkinen, R. N. Barnett, U. Landman, J. Phys. Chem. A, 1999, 103, 9573-9578.

[33] B. T. Qiao, J. X. Liang, A. Q. Wang, J. Y. Liu, T. Zhang, Chin. J. Catal., 2016, 37, 1580-1586.

[34] C. Y. Wang, G. Garbarino, L. F. Allard, F. Wilson, G. Busca, M. Flytzani-Stephanopoulos, ACS Catal., 2016, 6, 210-218.

[35] A. Corma, O. G. Salnikov, D. A. Barskiy, K. V. Kovtunov, I. V. Koptyug, Chem. Eur. J., 2015, 21, 7012-7015.

[36] M. Moses-DeBusk, M. Yoon, L. F. Allard, D. R. Mullins, Z. L. Wu, X. F. Yang, G. Veith, G. M. Stocks, C. K. Narula, J. Am. Chem. Soc., 2013, $135,12634-12645$.

[37] J. D. Kistler, N. Chotigkrai, P. X. Xu, B. Enderle, P. Praserthdam, C. Y. 
Chen, N. D. Browning, B. C. Gates, Angew. Chem. Int. Ed., 2014, 53, 8904-8907.

[38] Y. T. Shi, C. Y. Zhao, H. S. Wei, J. H. Guo, S. X. Liang, A. Q. Wang, T. Zhang, J. Y. Liu, T. L. Ma, Adv. Mater., 2014, 26, 8147-8153.

[39] Y. P. Zhai, D. Pierre, R. Si, W. L. Deng, P. Ferrin, A. U. Nilekar, G. W. Peng, J. A. Herron, D. C. Bell, H. Saltsburg, M. Mavrikakis, M. Flytzani-Stephanopoulos, Science, 2010, 329, 1633-1636.

[40] M. Yang, J. L. Liu, S. Lee, B. Zugic, J. Huang, L. F. Allard, M. Flytzani-Stephanopoulos, J. Am. Chem. Soc., 2015, 137, 3470-3473.

[41] F. R. Lucci, M. D. Marcinkowski, E. C. H. Sykes, J. L. Liu, M. Yang, M. Flytzani-Stephanopoulos, L. F. Allard, Nat. Commun., 2015, 6, 8550.

[42] J. Deng, H. B. Li, J. P. Xiao, Y. C. Tu, D. H. Deng, H. X. Yang, H. F. Tian, J. Q. Li, P. J. Ren, X. H. Bao, Energy Environ. Sci., 2015, 8, 1594-1601.

[43] J. Lin, B. T. Qiao, N. Li, L. Li, X. C. Sun, J. Y. Liu, X. D. Wang, T. Zhang, Chem. Commun., 2015, 51, 7911-7914.

[44] H. S. Wei, X. Y. Liu, A. Q. Wang, L. L. Zhang, B. T. Qiao, X. F. Yang, Y. Q. Huang, S. Miao, J. Y. Liu, T. Zhang, Nat. Commun., 2014, 5, 5634.

[45] B. Zhang, H. Asakura, J. Q. Zhang, J. Zhang, S. De, N. Yan, Angew. Chem. Int. Ed., 2016, 55, 8319-8323.

[46] S. Abbet, A. Sanchez, U. Heiz, W. D. Schneider, A. M. Ferrari, G. Pacchioni, N. Rösch, J. Am. Chem. Soc., 2000, 122, 3453-3457.

[47] J. H. Kwak, L. Kovarik, J. Szanyi, ACS Catal., 2013, 3, 2094-2100.

[48] E. J. Peterson, A. T. DeLaRiva, S. Lin, R. S. Johnson, H. Guo, J. T. Miller, J. H. Kwak, C. H. F. Peden, B. Kiefer, L. F. Allard, F. H. Ribeiro, A. K. Datye, Nat. Commun., 2014, 5, 4885.

[49] G. Vile, D. Albani, M. Nachtegaal, Z. P. Chen, D. Dontsova, M. Antonietti, N. Lopez, J. Perez-Ramirez, Angew. Chem. Int. Ed., 2015, 54, 11265-11269.

[50] H. R. Zhou, X. F. Yang, A. Q. Wang, S. Miao, X. Y. Liu, X. L. Pan, Y. Su, L. Li, Y. Tan, T. Zhang, Chin. J. Catal., 2016, 37, 692-699.

[51] G. Kyriakou, M. B. Boucher, A. D. Jewell, E. A. Lewis, T. J. Lawton, A. E. Baber, H. L. Tierney, M. Flytzani-Stephanopoulos, E. C. H. Sykes, Science, 2012, 335, 1209-1212.

[52] M. B. Boucher, B. Zugic, G. Cladaras, J. Kammert, M. D. Marcinkowski, T. J. Lawton, E. C. H. Sykes, M. Flytzani-Stephanopoulos, Phys. Chem. Chem. Phys., 2013, 15, 12187-12196.

[53] G. X. Pei, X. Y. Liu, A. Q. Wang, L. Li, Y. Q. Huang, T. Zhang, J. W. Lee, B. W. L. Jang, C. Y. Mou, New J. Chem., 2014, 38, 2043-2051.

[54] G. X. Pei, X. Y. Liu, A. Q. Wang, A. F. Lee, M. A. Isaacs, L. Li, X. L. Pan, X. F. Yang, X. D. Wang, Z. J. Tai, K. Wilson, T. Zhang, ACS Catal., 2015, 5, 3717-3725.

[55] X. X. Cao, A. Mirjalili, J. Wheeler, W. T. Xie, B. W. L. Jang, Fron. Chem. Sci. Eng., 2015, 9, 442-449.

[56] P. Aich, H. J. Wei, B. Basan, A. J. Kropf, N. M. Schweitzer, C. L. Marshall, J. T. Miller, R. Meyer, J. Phys. Chem. C, 2015, 119, 18140-18148.

[57] F. R. Lucci, M. T. Darby, M. F. G. Mattera, C. J. Ivimey, A. J. Therrien,
A. Michaelides, M. Stamatakis, E. C. H. Sykes, J. Phys. Chem. Lett, 2016, 7, 480-485.

[58] J. L. Liu, F. R. Lucci, M. Yang, S. Lee, M. D. Marcinkowski, A. J. Therrien, C. T. Williams, E. C. H. Sykes, M. Flytzani-Stephanopoulos, J. Am. Chem. Soc., 2016, 138, 6396-6399.

[59] S. R. Zhang, L. Nguyen, J. X. Liang, J. J. Shan, J. Y. Liu, A. I. Frenkel, A. Patlolla, W. X. Huang, J. Li, F. Tao, Nat. Commun., 2015, 6, 7938.

[60] J. C. Matsubu, V. N. Yang, P. Christopher, J. Am. Chem. Soc. 2015, 137, 3076-3084.

[61] R. Lang, T. B. Li, D. Matsumura, S. Miao, Y. J. Ren, Y. T. Cui, Y. Tan, B. T. Qiao, L. Li, A. Q. Wang, X. D. Wang, T. Zhang, Angew. Chem. Int. Ed. 2016, 55, 16178 .

[62] L. B. Wang, W. B. Zhang, S. P. Wang, Z. H. Gao, Z. H. Luo, X. Wang, R. Zeng, A. W. Li, H. L. Li, M. L. Wang, X. S. Zheng, J. F. Zhu, W. H. Zhang, C. Ma, R. Si, J. Zeng, Nat. Commun., 2016, 7, 14036.

[63] Z. W. Huang, X. Gu, Q. Q. Cao, P. P. Hu, J. M. Hao, J. H. Li, X. F. Tang, Angew. Chem. Int. Ed., 2012, 51, 4198-4203.

[64] Y. X. Chen, T. Kasama, Z. W. Huang, P. P. Hu, J. M. Chen, X. Liu, X. F. Tang, Chem. Eur. J., 2015, 21, 17397-17402.

[65] P. P. Hu, Z. Amghouz, Z. W. Huang, F. Xu, Y. X. Chen, X. F. Tang, Environ. Sci. Technol., 2015, 49, 2384-2390.

[66] Y. X. Chen, Z. W. Huang, M. J. Zhou, Z. Ma, J. M. Chen, X. F. Tang, Environ. Sci. Technol., 2017, 51, 2304-2311.

[67] Y. X. Chen, Z. W. Huang, P. P. Hu, J. M. Chen, X. F. Tang, Catal. Commun., 2016, 75, 74-77.

[68] F. Xu, Z. W. Huang, P. P. Hu, Y. X. Chen, L. Zheng, J. Y. Gao, X. F. Tang, Chem. Commun., 2015, 51, 9888-9891.

[69] S. Yang, J. Kim, Y. J. Tak, A. Soon, H. Lee, Angew. Chem. Int. Ed., 2016, 55, 2058-2062.

[70] S. Back, J. Lim, N. Y. Kim, Y. H. Kim, Y. Jung, Chem. Sci., 2017, 8, 1090-1096.

[71] X. G. Li, W. T. Bi, L. Zhang, S. Tao, W. S. Chu, Q. Zhang, Y. Luo, C. Z. Wu, Y. Xie, Adv. Mater., 2016, 28, 2427-2431.

[72] H. L. Fei, J. C. Dong, M. J. Arellano-Jimenez, G. L. Ye, N. D. Kim, E. L. G. Samuel, Z. W. Peng, Z. Zhu, F. Qin, J. M. Bao, M. J. Yacaman, P. M. Ajayan, D. L. Chen, J. M. Tour, Nat. Commun., 2015, 6, 8668.

[73] H. J. Qiu, Y. Ito, W. T. Cong, Y. W. Tan, P. Liu, A. Hirata, T. Fujita, Z. Tang, M. W. Chen, Angew. Chem. Int. Ed., 2015, 54, 14031-14035.

[74] P. Q. Yin, T. Yao, Y. E. Wu, L. R. Zheng, Y. Lin, W. Liu, H. X. Ju, J. F. Zhu, X. Hong, Z. X. Deng, G. Zhou, S. Q. Wei, Y. D. Li, Angew. Chem. Int. Ed., 2016, 55, 10800-10805.

[75] B. Wurster, D. Grumelli, D. Hötger, R. Gutzler, K. Kern, J. Am. Chem. Soc., 2016, 138, 3623-3626.

[76] X. J. Cui, J. P. Xiao, D. H. Deng, X. H. Bao, Y. H. Wu, W. H. Zhang, P. P. Du, R. Si, H. X. Yang, H. F. Tian, J. Q. Li, Angew. Chem. Int. Ed., 2016, $55,6708-6712$.

[77] H. B. Zhang, J. Wei, J. C. Dong, G. G. Liu, L. Shi, P. F. An, G. Zhao, J. T. Kong, X. J. Wang, X. G. Meng, J. Zhang, J. H. Ye, Angew. Chem. Int. Ed., 2016, 55, 14310-14314.

\title{
单原子催化的最新进展
}

\author{
韩 冰 ${ }^{\mathrm{a}, \mathrm{b}, \dagger}$, 郎 点 ${ }^{\mathrm{a}, \dagger}$, 乔波涛 ${ }^{\mathrm{a}, *}$, 王爱琴 ${ }^{\mathrm{a}}$, 张 涛 $^{\mathrm{a}}$ \\ a中国科学院大连化学物理研究所催化基础国家重点实验室, 辽宁大连116023 \\ b 中国科学院大学, 北京100049
}

摘要: 单原子催化剂由于其自身兼具均相催化剂的 “孤立活性位点” 和多相催化剂易于循环使用的特点, 近年来受到了广 泛关注. 本综述概括了2015至2016年单原子催化领域的重要进展, 重点介绍了新的催化剂制备方法、单原子金催化剂在CO 氧化中的进展、单原子钯/铂催化的选择性加氢反应以及铂或非贵金属单原子催化剂在电化学中的应用等. 在催化剂的合 
成方面, 用传统的湿化学方法制备的单原子催化剂通常金属负载量较低, 使得催化剂的常规表征比较困难. 最近发展的一 系列新型合成方法例如原子层沉积法、高温蒸汽转移法、光介还原法以及热解法等制备 $\mathrm{M}-\mathrm{N}-\mathrm{C}$ 等非贵金属催化剂等, 尽 管有不同程度的局限性, 但均可以成功制备高负载量的单原子催化剂. 单原子催化剂的载体得到了拓展, 除传统的金属氧 化物外, 金属有机框架材料和二维材料等均被用于单原子催化剂的制备. 在单原子催化剂的应用方面, 金由于较高的电负 性和与氧的弱相互作用能力, 因而与氧化物载体作用较弱, 不易形成单原子催化剂. 但近期报道了成功制备的单原子金催 化剂, 在 $\mathrm{CO}$ 氧化反应、乙醇脱氢和二烯加氢反应中都有不错的进展. 本文还介绍了铂和钯单原子(合金)催化剂在加氢反应 中的优异活性及选择性, 表明了单原子催化剂在选择性上的优势. 将一种金属掺杂到另一种金属基底中制备的单原子合 金催化剂也因其特异的性能备受关注. 此外, 对于化工生产中典型的均相催化反应, 如氢甲酰化, 单原子催化剂在无外加 膦配体的情况下表现出高活性的同时还能很好地控制化学选择性, 甚至达到令人满意的区域选择性, 从实验上证明了单原 子催化剂有望作为沟通均相催化和多相催化的桥梁. 单原子催化剂在电催化和光催化中也得到了快速发展. 铂单原子催 化剂因其高原子利用率和高稳定性, 在析氢反应和氧还原反应中有着良好的应用前景. 另一方面, 非贵金属特别是Co单原 子催化剂在光电催化中因其优异的活性和巨大潜力得到了较深入的研究. 除了上述进展, 单原子催化领域还有许多基本 问题需要继续深入研究, 对单原子催化剂更加全面透彻的认识将为设计发展新型催化体系, 扩展单原子催化领域提供指导 和借鉴.

关键词: 单原子催化; 催化剂合成; 一氧化碳氧化; 加氢反应; 电催化

收稿日期: 2017-04-24. 接受日期: 2017-06-07. 出版日期: 2017-09-05.

*通讯联系人. 电话: (0411)84379416; 传真: (0411)84685940; 电子信箱: bqiao@dicp.ac.cn

†共同第一作者.

基金来源：国家自然科学基金(21606222，21303184，21573232); 中国博士后基金面上资助(2016M601350); 中国科学院战略性先 导科技专项 (XDB17020100); 国家重点研发计划 “纳米科技”重点专项(2016YFA0202801); 辽宁省科技厅院士基金 (2015020086-101).

本文的英文电子版由Elsevier出版社在ScienceDirect上出版(http://www.sciencedirect.com/science/journal/18722067). 